\title{
Responsabilidad Social Empresarial a las Responsabilidades en Derechos Humanos ${ }^{1}$ Corporate Social Responsibility to Human Rights Responsibilities
}

Luis Alejandro, Rodríguez-Cruz ${ }^{2}$

https://orcid.org/0000-0002-4714-9238

Verónica, Cuevas Pérez ${ }^{3}$

https://orcid.org/0000-0001-6901-1398

Víctor Néstor, Aguirre Sotelo ${ }^{4}$

https://orcid.org/0000-0003-0469-2414

Universidad Autónoma de Nuevo León, México

\section{RESUMEN}

Este articulo tiene como objetivo explicar la relación asimétrica que se encuentra en la Responsabilidad Social Empresarial (RSE) y los Derechos Humanos (DH), iniciando con el origen de la Responsabilidad Social y como le da paso a la existencia Empresarial, tomando como base diferentes eventos claves como la Cumbre del Milenio y el Pacto Global de la Organización de las Naciones Unidas (ONU), así como documentos esenciales para expresar conforme a la teoría, como los Diez principios del Pacto Global, Los Principios Rectores de las Naciones Unidas; haciendo una reflexión acerca de los desafíos empresariales para cumplir con sus responsabilidades y no afectar los derechos humanos. La conclusión se centra en exponer esa estrecha relación de la RSE y Derechos Humanos, dando recomendaciones a futuros trabajos en la misma línea de investigación.

Palabras clave: Consulta Previa Libre e Informada, Derechos Humanos, Organización de las Naciones Unidas, Responsabilidad Social, Responsabilidad Social Empresarial.

\section{ABSTRACT}

The objective of this article is explain the asymmetric relation that is found in the Corporate Social Responsibility and the Human Rights, starting with the origin of the Social Responsibility and the existent business existence, based on different key events such as the Millennium Summit and the Global Compact of the United Nations (UN), as well as essential documents to express according to the theory, reflecting on business challenges to fulfill their responsibilities and not affect human rights. The center of this conclusion is exposing the relation of RSE and Human Rights, giving recommendations for future work in the same line of investigation.

Keywords: Free and Informed Prior Consultation, Human Rights, United Nations Organization, Social Responsibility, Corporate Social Responsibility.

\section{Recibido: 25 de Octubre 2018 - Aceptado: 29 de Febrero 2019}

Cómo referenciar este artículo:

Rodríguez-Cruz, L. A., Cuevas Pérez, V., \& Aguirre Sotelo, V. N. (2018). Responsabilidad Social Empresarial a las Responsabilidades en Derechos Humanos . Revista Política, Globalidad y Ciudadanía, 63-79. Recuperado de http://revpoliticas.uanl.mx/index.php/RPGyC/article/view/136

\section{(c) $(7)$}

1 Artículo de revisión derivado del proyecto de investigación: Responsabilidad Social Empresarial a las Responsabilidades en Derechos Humanos.

2 Doctor en Filosofía con Orientación en Relaciones Internacionales, Negocios y Diplomacia. Profesor-Investigador en la Universidad Autónoma de Nuevo León. Email: alejandro_rdz88@hotmail.com

3 Doctora en Filosofía con acentuación en Ciencias Políticas. Profesora tiempo completo en la Universidad Autónoma de Nuevo León. Email: veronicacp70@hotmail.com

4 Doctor en Filosofía con acentuación en Ciencias Políticas. Profesor tiempo completo en la Universidad Autónoma de Nuevo León. Email: victor.aguirrest@uanl.edu.mx

Revista Política, Globalidad y Ciudadanía, Vol. 5 No. 10, Julio - Diciembre 2019, Universidad Autónoma de Nuevo León, Monterrey, México, ISSN 2395-8448. 63-79. http://revpoliticas.uanl.mx/index.php/RPGyC/article/view/136 


\section{1.- INTRODUCCIÓN}

En los últimos años, con el fenómeno de la globalización, surgen cambios y nuevas estrategias entre las empresas y los mercados para competir a nivel internacional. Emerge también un nuevo paradigma buscando medir la sustentabilidad económica, social y ecológica. La medición de este paradigma nace ante la observación en la nueva gestión de hacer negocio a través de la Responsabilidad Social Empresarial (RSE).

La exigencia ética de sostenibilidad invita a redefinir los modelos de gestión de las organizaciones y los territorios locales, nacionales y regionales, la responsabilidad social no es acción social que se mantenga al margen de la actividad principal de la organización, sino un nuevo sistema de gestión de la organización.

La competitividad en las empresas es cada vez mayor, es por esto que para su supervivencia deben atraer a los clientes con argumentos buenos y diferentes a las demás organizaciones. La responsabilidad social es uno de los argumentos más importantes, de esta manera la organización que se funda en este argumento como lo es la responsabilidad social, presenta una imagen más transparente y sincera a los clientes. Es por esto que surge la necesidad de crear empresas que buscan crear un buen ambiente social, donde exista el respeto al trabajador, la ética y la responsabilidad social.

En la Actualidad la Responsabilidad Social se ha ido evolucionando y se han arraigado en diferentes Organismos Internacionales, hoy se habla ya de una manera sólida de sustentabilidad; hoy se han realizado grandes documentos como el Libro Verde y el Blanco; y se han publicado guías extraordinarias como las Directrices de la Organización para la Cooperación y el Desarrollo Económico (OCDE) o la tan ansiada ISO26000; además la economía global ha hecho que las acciones sociales se conviertan en una herramienta estratégica de negocio. La razón de ser de las compañías no debe centrarse en resolver las necesidades de los sectores menos atendidos, sin embargo, sí es necesario que conciban la idea de generar valor social y económico.

La RSE no es una obligación legal que tiene que cumplir la organización, pero cabe mencionar que el mercado ha aprendido a diferenciar de entre aquellas empresas que realmente están comprometidas socialmente de aquellas que no lo están. El uso de la RSE en pequeñas y medianas empresas es fundamental ya que son las que más contribuyen a la economía y a la creación de puestos de trabajo. Las iniciativas sociales van de la mano con la misión y visión de la empresa, se debe de mantener un balance entre los negocios y las actividades sociales.

La RSE ha de ser ética en el sentido de conversión sobre las reflexiones filosóficas y morales hacia las corporaciones para que guíen los comportamientos de las personas dentro de las ejecuciones y el cumplimiento de los fines estipulados, de igual manera, ha de gozar de integridad y neutralidad a todos sus grupos de interés, generando oportunidad en igualdad de condiciones y permitiendo elementos equitativos asociados al aspecto coherente de sus intenciones y realizaciones; la coherencia es un aspecto de la RSE enfocado a la equivalencia entre las decisiones plasmadas y las acciones tomadas en la consecución de

Revista Política, Globalidad y Ciudadanía, Vol. 5 No. 10, Julio - Diciembre 2019, Universidad Autónoma de Nuevo León, Monterrey, México, ISSN 2395-8448. 63-79. http://revpoliticas.uanl.mx/index.php/RPGyC/article/view/136 
los planes y estrategias por medio de gestiones y prácticas que reflejen la veracidad, seguridad y viabilidad de las expectativas e intereses de las partes relacionadas y por último ha de reconocer el dialogo como construcción de tácticas de administración y dirección compartida mediante la participación activa en posibilitar los juicios en prácticas concretas Adarme Durán, J. S., \& Maldonado Vásquez, J. A. ( 2020).

En un mundo globalizado, donde las empresas son tan poderosas, mucho más que los países, los Estados-Naciones van perdiendo un poco de poder. Ya no hay fronteras, hoy el comercio es muy importante, es por eso que la RSE de la empresa es muy importante y va más allá de vender un buen producto, de satisfacer a sus consumidores, de pagar bien a sus obreros o darles alguna ganancia a sus inversionistas, mientras más grande sea la empresa, más responsabilidades tiene.

Las personas frecuentemente se preguntan si las empresas tienen sus códigos de ética. Si hacen informes respecto a lo que hicieron en cuestión de responsabilidad social, si es qué hay algo que realmente los impulsa o si sólo lo hacen para tener un buen marketing, las personas deben diferenciar si estas actividades de ética realmente corresponden a los ideales de la empresa o solo es para crear una imagen y posicionar su producto, sin embargo, la RSE es algo que se debe de hacer por el simple hecho de estar inmersos en la sociedad.

Y es aquí donde surge la relación asimétrica de la RSE y los $\mathrm{DH}$, ya que nace a partir de que las empresas puedan ser sancionadas por violar las normas internacionales de protección de los derechos humanos siendo así un elemento esencial obligatorio para estas, por lo cual esta relación las invita a cumplir con obligaciones jurídicas que deben ser respetadas en cualquier parte donde necesiten desarrollar proyectos, asumiendo los tratados internacionales en derechos humanos, las empresas al tener esta Responsabilidad Social (RS) le garantiza permanencia en una cultura de la legalidad, contribuyendo al bienestar social mundial.

La pregunta es ¿Cómo es el impacto de las Empresas Socialmente Responsables en términos de Derechos Humanos para los grupos vulnerables mediante los proyectos implantados en territorios de estos? Nuestro objetivo es explicar la relación asimétrica que se encuentra en la Responsabilidad Social Empresarial (RSE) y los Derechos Humanos (DH) que con el tiempo ha ido evolucionando de pasar de una simple distinción como empresa que emerge con políticas de RSE a su impacto en los DH de los grupos vulnerables.

La cuestión de la responsabilidad empresarial en el ámbito del derecho internacional no es una cuestión que haya aparecido recientemente en el escenario global; por el contrario, es un tema que durante cuarenta años se ha desarrollado en múltiples frentes y con distintos propósitos, desde el establecimiento de un nuevo orden económico internacional hasta la consagración de estándares laborales y de responsabilidad social empresarial; desde 1977 se buscó desarrollar un código de conducta para las empresas transnacionales que regulara los diferentes aspectos y efectos de su actividad, dentro de cuyos estándares se encontraba una referencia sobre la obligación de las empresas transnacionales de respetar los derechos humanos y las libertades fundamentales de los países en que operen. (Cantú, Rivera, H. 2017). 
Lo que hace que exista una problemática que se está haciendo más visible y común, dentro del tema relación entre empresa y derechos humanos, esto por la creciente evidencia que dejan ver las organizaciones de ciudadanos preocupados por la violación de los derechos humanos, así como las instituciones que se dedican a esto; específicamente en el desarrollo de proyectos que impactan en territorios de grupos vulnerables.

Ghys, T. (2019) menciona que los derechos humanos crean argumentos y obligaciones legales que hacen que se protejan y se respeten en diferentes casos que son enmarcados en términos de ineficacia lamentable como el crimen o la corrupción, además de señalar la necesidad de continuar realizando una mejora institucional que aumente la dignidad de todas las personas.

Esa situación viene haciendo cada vez más evidentes los efectos que frecuentemente la actividad empresarial puede tener sobre los derechos humanos. La actividad económica, tanto pública como privada suele tener un impacto directo sobre las personas y comunidades que se desenvuelven tanto en su entorno como en su interior. Las consecuencias sobre el medio ambiente, la salud, la afectación de los derechos de las comunidades, especialmente indígenas, la vulneración de los derechos fundamentales de sus trabajadores, particularmente a través de la adopción de medidas discriminatorias de distinta naturaleza, son los ejemplos más reiterativos de una realidad cada vez más acuciante. (Ljubetic, Y. 2017).

Para decir que una empresa pueda llegar a tener responsabilidad internacional se suele tomar como referencia que tengan o no personalidad legal internacional en analogía con otros actores no estatales. Ello supondría que se pasara de un concepto tradicional de responsabilidad vertical en derechos humanos a un concepto de horizontalidad que gana fuerza a medida que los actores no estatales violan la dignidad y los derechos humanos. (Tapia Gutiérrez, 2014).

La relación empresa - derechos humanos, es sencillamente invitar a cumplir a los actores privados a cumplir con las obligaciones en DH lo cual es importante para ambos actores, ya que se cumple con no violar los derechos de grupo vulnerables y las empresas pueden maximizar sus utilidades lo cual es su principal objetivo al momento de desarrollo proyectos que pudiesen impactar dichos grupos.

\section{2.- FUNDAMENTO TEÓRICO}

\section{Responsabilidad Social}

Compromiso u obligación así es llamada la responsabilidad social que involucra a los miembros de una sociedad, como individuo o como parte de un grupo social que al momento de tomar una decisión arrojara un impacto positivo o negativo.

El concepto de responsabilidad ha sido un término de referente común para diferentes ámbitos de la vida, y el derecho lo ha trabajado ampliamente desde la teoría general de la responsabilidad. En busca de un sentido concreto, el derecho ha concebido la responsabilidad a través de los criterios de imputación. Para comprender el término de responsabilidad social, el análisis

Revista Política, Globalidad y Ciudadanía, Vol. 5 No. 10, Julio - Diciembre 2019, Universidad Autónoma de Nuevo León, Monterrey, México, ISSN 2395-8448. 63-79. http://revpoliticas.uanl.mx/index.php/RPGyC/article/view/136 
debe partir de entenderla como un compromiso ético-moral de individuos, grupos, entidades, organismos e instituciones con la sociedad. (Torres, J. B., \& Alemán, L. S. 2020).

La responsabilidad social tiene su origen desde el inicio de la historia, desde nuestros antepasados, en lo cual los principales actores era la misma humanidad, para que esto se realizara, podemos observar en las palabras del político - filosófico Cicerón en su libro primero de " Los Deberes" donde explica sobre los deberes que tiene el hombre hacia la sociedad y hacia el mismo y plantea que existe únicamente una ley verdadera, la cual es la recta razón, que de acuerdo con la naturaleza, gobierna sobre toda la humanidad, es infinita y no cambia. Esta ley estimula a la sociedad a cumplir con sus deberes, prohibiéndoles hacer el mal.

La responsabilidad permite establecer las características que debe tener un ciudadano del mundo con la competencia de la responsabilidad social, una de las definiciones más específicas que llama más la atención, es que la responsabilidad social es la preocupación por las consecuencias ambientales y sociales de la actividad humana o de las organizaciones.

EL Libro Verde de la Comisión Europea, menciona que la responsabilidad social es "la responsabilidad de las empresas por sus impactos en la sociedad".

La responsabilidad social es el compromiso contraído por las acciones u omisiones de cualquier individuo o grupo que generen un impacto en la sociedad; pudiendo recaer éstas en una persona, organización, gobierno o empresa. Dichas acciones suelen traer consigo una valoración positiva o negativa por parte de la comunidad. (Comisión Europea, 2001).

En un entorno de economía globalizada, las relaciones productivas y sociales cambiaron radicalmente, evidenciando la incapacidad del Estado para proporcionar respuestas. Ahora la ciencia y la tecnología están aportando estructuras de oportunidad que marginan a amplios sectores de la población y generan conflictos institucionales, al tiempo que las instituciones financieras, incluidas las públicas, se observan disfuncionales como promotoras del crecimiento. Bajo esta lógica la pobreza parece tener un nuevo y más severo rostro en la medida que la globalización ha producido acentuados índices de desigualdad, marginación y exclusión social. (Kliksberg, 2004).

La responsabilidad social no es algo que va de paso sin dejar huella, sino una obligación universal para asegurar la sostenibilidad social y ambiental de nuestro modo de producción y consumo en un planeta frágil en el cual todos tenemos iguales derechos a una vida digna. (Vallaeys, F., De la Cruz, C., \& Sasia, P. M., 2009).

\section{Responsabilidad Social Empresarial}

Cuando se habla de Responsabilidad Social Empresarial, se tiene que enfatizar en el origen de su existencia, y quien la origino fue la Responsabilidad Social con la cual hablamos de tener una inspiración voluntaria, de aceptar el compromiso que tenemos con nuestra sociedad, de hacer el cambio, de ser maduros y hacer consciencia en los demás ante los problemas que se nos presentan como sociedad, el cual nos hará adoptar hábitos que nos ayudaran a resolver esas 
problemáticas que se nos pudiesen presentar y causar un fuerte impacto.

Martínez (2005) menciona a la Responsabilidad Social Empresarial como "el compromiso audible de la empresa con los valores éticos que dan un sentido humano a su empeño por el desarrollo sostenible buscando una estrategia de negocios que integre el crecimiento económico con el bienestar social y la protección ambiental".

Aguilera Castro, A. \& Puerto Becerra, D. P (2012) definen a la Responsabilidad Social Empresarial como una decisión de carácter voluntario, la empresa determina deliberadamente si asume o no ese compromiso. Una vez asumida, la Responsabilidad Social Empresarial debe ir orientada coherentemente con los principios de la empresa y con el cumplimiento integral de la visión que se ha establecido tanto a nivel interno como a nivel externo; considerando las expectativas de las partes interesadas (stakeholders), demostrando el respeto por los valores éticos, por la gente, por las comunidades, por el medio ambiente, y contribuyendo, de esta manera, con la construcción del bien común.

La RSE nace en los años 20, pero fue en los años 30 cuando se incrementó debido a la gran depresión, la cual ocasionó desempleo y pobreza, en EEUU, Europa y Latinoamérica. En 1950 y 1960 el mercado norteamericano comenzó a tomar más conciencia acerca de la labor social, es en estos años donde las empresas comienzan a crear mecanismos para incentivar las contribuciones caritativas, que además favorece a las empresas ya que estas contribuciones representan menos impuestos para las empresas.

Es en este tiempo que el autor Howard R. Bowen (conocido como el Padre de la RSE) publicó el libro "Social Responsibilities of the Businessman" y fijó para siempre las bases de lo que hoy entendemos como responsabilidad social empresarial.

Es en este libro es donde por primera vez se define a la RSE como "las obligaciones de los empresarios para impulsar políticas corporativas para tomar decisiones o para seguir líneas de acción que son deseables en términos de los objetivos y valores de la sociedad"; lo cual expresa la relación entre la empresa y la sociedad.

En 1960 algunos empresarios plantean la idea de la Responsabilidad Social Empresarial, pero es en el año de 1990 cuando este concepto fue tomando fuerza y se ha ido evolucionando tras el desarrollo de la globalización, la actividad económica, la conciencia hacia el medio ambiente y las nuevas tecnologías. La importancia por la RSE no es nueva, desde mediados del siglo XX se consideraba que las empresas deberían tomar en cuenta las consecuencias sociales de sus decisiones. También en esta segunda parte del siglo XX aumenta la importancia de la sensibilidad social respecto a la ética en los negocios.

En 1999 en la cumbre económica mundial, celebrada en Suiza, el secretario general de las Naciones Unidas realizó una invitación a las empresas a cooperar dando muestras de una buena ciudadanía global, propuso un acuerdo mundial que incluyera tres áreas: derechos humanos, condiciones de trabajadores y protección del medio ambiente, conciliando así los intereses 
comerciales y sociales.

Este hecho dio origen a lo que hoy se conoce como "el pacto mundial" que es la fuente inspiradora de la RSE.

\section{La cumbre del milenio y el pacto global de la ONU.}

La cumbre del milenio es un factor clave a nivel internacional para lo que hoy es la defensa en derechos humanos y las responsabilidades que tienen las empresas en objeto de Responsabilidad Social a nivel mundial.

La cumbre del milenio de las naciones unidas, siendo parte integral de la asamblea del milenio se llevó acabo el 6 de septiembre del año 2000 en Nueva York, aprobada el 15 de marzo del mismo año.

Entre los objetivos con la intención declarada de promover la paz, la seguridad y el desarme, los líderes mundiales se comprometieron a fortalecer el estado de derecho y a garantizar el cumplimiento de las decisiones de la Corte Internacional de Justicia, a fin de proporcionar a las Naciones Unidas los recursos necesarios para la prevención de conflictos y su resolución pacífica, y para tomar medidas contra el problema internacional de las drogas y el terrorismo.

Los líderes mundiales que se reunieron en la Cumbre comprometieron a sus naciones a una nueva alianza mundial para reducir la pobreza extrema y establecieron una serie de metas con plazos concretos, con el 2015 como fecha límite, que se conocen desde la Cumbre del Milenio como los Objetivos de Desarrollo del Milenio.

Dentro de la Resolución aprobada por la Asamblea General 55/2 Declaración del Milenio, nos enfocamos en el punto I. Valores y principios, numero 6 específicamente en el de "Responsabilidad común": La responsabilidad de la gestión del desarrollo económico y social en el mundo, lo mismo que en lo que hace a las amenazas que pesan sobre la paz y la seguridad internacionales, debe ser compartida por las naciones del mundo y ejercerse multilateralmente.

Por ser la organización más universal y representativa de todo el mundo, las Naciones Unidas deben desempeñar un papel central a ese respecto.

El tema del respeto a los derechos humanos para la ONU es de suma importancia, así que dentro de sus estrategias para evitar las violaciones de derechos humanos opto por una metodología diferente que implementara el buen comportamiento empresarial, ya que estaba identificando que de forma directa o indirecta elevadas violaciones a los derechos humanos por parte de las empresas, es así que de la mano del secretario general Kofi Annan en 1999, en el Foro Económico Mundial de Davos, se extendió la invitación a los líderes mundiales empresariales a llevar a cabo un importante Pacto Global, que por voluntad propia deberían integrar principios que estuviesen dentro de la normatividad internacional a sus prácticas y políticas internas empresariales. 
Es así como el Pacto Global de las Naciones Unidas fue lanzado en julio del año 2000, como una plataforma política y un marco practico para las empresas comprometidas con la sostenibilidad y las prácticas empresariales responsables, la cual pretende armonizar en todo el mundo las operaciones y estrategias comerciales con diez principios universalmente aceptados en los ámbitos de los derechos humanos, los estándares laborales, el medio ambiente y la lucha contra la corrupción.

A través de un amplio abanico de vías de trabajo especializadas, instrumentos de gestión, recursos y programas temáticos, el Pacto Mundial de las Naciones Unidas se propone avanzar hacia el logro de dos objetivos complementarios: Incorporar los diez principios en las actividades empresariales de todo el mundo; y Catalizar las acciones en apoyo de los objetivos más amplios de las Naciones Unidas, incluidos los objetivos de desarrollo del Milenio.

El Pacto Mundial de las Naciones Unidas no es un instrumento normativo, sino una iniciativa voluntaria basada en la rendición publica de cuentas, la transparencia y la divulgación de información destinada a complementar la regulación y ofrecer un espacio para la innovación.

El Pacto Mundial se divide en cuatro áreas en las que las empresas deben realizar esfuerzos: derechos humanos, derechos laborales, medio ambiente y combate a la corrupción. Tal como se anuncia, este proyecto se trata de una plataforma para el desarrollo, la implementación y la revelación de políticas y prácticas corporativas responsables y sostenibles, que resulten en el alineamiento de operaciones y estrategias comerciales con los diez principios en ella enunciados, en un diálogo permanente y conjunto, y en un esfuerzo colectivo por apoyar la implementación de los Objetivos de Desarrollo del Milenio de las Naciones Unidas (UN Millennium Development Goals). Al unirse a tal iniciativa, las empresas se comprometen a entregar anualmente un informe en el que se detallen la forma en que los diez principios del Pacto Mundial son aplicados, y a hacer un donativo anual cuyo monto depende del tamaño de la sociedad.

El Pacto Global es un marco práctico para desarrollar, implantar y divulgar políticas y prácticas de sostenibilidad empresarial, que ofrece a las organizaciones que se adhieren, una amplia gama de recursos y herramientas de gestión para ayudarles a implementar modelos de negocio y desarrollo sostenible. (Comité Minero Energético (CME) Guías Colombia en Empresas, DDHH y DIH, Pacto Global Red Colombia , 2019)

Dicho proyecto, a pesar de ser uno de los más aceptados por la comunidad empresarial - esencialmente por su laxedad regulatoria_, también ha sido objeto de fuertes críticas por parte de las organizaciones no gubernamentales y de la sociedad civil, ya que consideran que al no existir algún mecanismo de regulación o control, las empresas pueden hacer uso de la propaganda y logotipos de la iniciativa sin tener que cumplir con sus compromisos adoptados, ni verdaderamente esforzarse por mejorar sus récords en materia de derechos humanos. (Cantú Rivera, H. 2013)

Finalmente, el objetivo del pacto global fue promover el diálogo social para la constitución de una ciudadanía corporativa global, que posibilite conciliar intereses de empresas, con 
demandas y valores de la sociedad civil.

Este cambio creo en los miembros de las organizaciones mayor interés en los derechos de los trabajadores y sobre los instrumentos para obligar al respeto de estos. Algunas influencias que han ayudado a la evolución de la RSE son el desarrollo constante de la globalización, la liberalización del comercio, el desarrollo ambiental sostenible, la acelerada degeneración del medio ambiente y la exclusión de diferentes grupos en la sociedad

\section{Los diez principios del pacto global}

El objetivo de los diez principios del pacto global es invitar a las empresas a hacer conciencia para que apoyen, apliquen y se comprometan a influir en los derechos humanos, en el medio ambiente, en la lucha contra la corrupción y la cuestión laboral de la sociedad.

Espinoza Santeli, (2016), menciona que las empresas adheridas al Pacto Global se clasifican en tres categorías: la primera categoría es la de plataforma de aprendizaje en la cual las empresas pueden emitir sus Cop's (Comunicación del Progreso) sin cumplir con todos los requisitos que exige el Pacto Mundial; la plataforma está disponible para ser utilizada una sola vez y las empresas tienen un periodo máximo de un año para cumplir con todos los requisitos. La segunda categoría es la de nivel activo, aquí se encuentran todas las empresas que cumplen disciplinadamente todos los requisitos requeridos por el Pacto Mundial y en caso de no reportar sus Cop's corren el riesgo de ser expulsadas. La última categoría es la de nivel avanzado, aquí las empresas se enfocan en mejorar sus niveles de sostenibilidad y rendimiento demostrando que cumplen cada uno de los principios del Pacto Mundial.

Los principios del pacto global están enfocados principalmente en los derechos humanos, los cuales deben ser apoyados y respetados por las empresas, las cuales no deben ser cómplices de violarlos en ninguna instancia.

En la cuestión laboral, las empresas deben apoyar la negociación laboral, no fomentar el trabajo forzado, erradicar el trabajo infantil y acabar con la discriminación en el empleo y la ocupación.

Con el medio ambiente, se deberá prevenir cualquier cosa que lo afecte y fomentar iniciativas que ayuden a la responsabilidad ambiental, apoyándose en el desarrollo y difusión de la tecnología que respete al medio ambiente y por último eliminar la corrupción y el soborno en toda instancia. 
Tabla 1 Principios del Pacto Global

PRINCIPIOS

PACTO GLOBAL

DERECHOS HUMANOS

Principio 1

Las empresas deben apoyar y respetar la protección de los derechos humanos fundamentales reconocidos universalmente.

Principio 2

Las empresas deben asegurarse de que no son cómplices de la vulneración de los derechos humanos.

Principio 3

Las empresas deben apoyar la libertad de asociación y el reconocimiento efectivo del derecho a la negociación colectiva.

\section{ESTANDARES LABORALES}

\begin{tabular}{l|l}
\hline Principio 4 & $\begin{array}{l}\text { Las empresas deben apoyar la eliminación } \\
\text { de toda forma de trabajo forzoso o realizado } \\
\text { bajo coacción. }\end{array}$ \\
\hline Principio 5 & $\begin{array}{l}\text { Las empresas deben apoyar la erradicación } \\
\text { del trabajo infantil. }\end{array}$ \\
\hline Principio 6 & $\begin{array}{l}\text { Las empresas deben apoyar la abolición de } \\
\text { las prácticas de discriminación en el empleo y } \\
\text { la ocupación. }\end{array}$ \\
\hline
\end{tabular}

\begin{tabular}{c|l}
\hline Principio 7 & $\begin{array}{l}\text { Las empresas deberán mantener un enfo- } \\
\text { que preventivo } \\
\text { que favorezca el medio ambiente. }\end{array}$ \\
\hline Principio 8 & $\begin{array}{l}\text { Las empresas deben fomentar las iniciati- } \\
\text { vas que promuevan una mayor responsabili- } \\
\text { dad ambiental. }\end{array}$ \\
\hline Principio 9 & $\begin{array}{l}\text { Las empresas deben favorecer el desarro- } \\
\text { llo y la difusión de las tecnologías respetuosas } \\
\text { con el medio ambiente. }\end{array}$ \\
\hline
\end{tabular}

Principio 10

\section{ANTICORRUPCION}

\begin{tabular}{l|l}
\hline Principio 10 & $\begin{array}{l}\text { Las empresas deben trabajar en contra de } \\
\text { la corrupción en todas sus formas, incluidas } \\
\text { la extorsión y el soborno. }\end{array}$
\end{tabular}

Fuente: Elaboración Propia. (2019)

Principales factores en los cuales las empresas deben apoyar, aplicar e influir para cumplir con la Responsabilidad Social Empresarial en Derechos Humanos. 
La creación de los diez principios del Pacto Global fortalece el cambio de perspectiva de la Responsabilidad Social, dejando atrás solamente el cumplimiento de una responsabilidad con la sociedad, ahora ratifica que en su deber de cumplir con la sociedad se compromete a no violar sus derechos en cualquier situación que le competa.

Jonh Ruggie, Representante especial del secretario general de la ONU sobre empresas y derechos humanos

El respeto a los derechos humanos es fundamental para cualquier instancia a cumplir, y es así que tomamos de base a John Ruggie, quien siendo profesor de Harvard fue nombrado representante especial del secretario general de la ONU sobre empresa y derechos humanos con el único fin de desarrollar un proceso inspirado en el Pacto Global que pudiera sustituir las Normas sobre las responsabilidades de las empresas trasnacionales y otras empresas comerciales en la esfera de los derechos humanos, elaboradas en el 2003, cuyas normas imponían obligaciones de protección y promoción de los derechos humanos a las empresas, las cuales no eran equivalentes a las del Estado.

El proceso de Ruggie a lo que hoy se le llama Principios Rectores de las Naciones Unidas sobre empresas y derechos humanos, empezó señalando y aclarando normas uniformes sobre la responsabilidad social empresarial, precisar la función del Estado en ese campo, el proceso tuvo varias fases, la primera "el estado del arte" donde se pretendían equiparar las obligaciones de las empresas con el estado, la segunda Política denominada Marco "Proteger, respetar y remediar" la cual agrupaba una serie de análisis e iniciativa que estaban dispersas, y la tercera poner en práctica el marco y dar recomendaciones para su implementación orientando a Estados, empresas y otras partes interesadas y fue así como John Ruggie, presenta en el 2011 al Consejo de Derechos Humanos las recomendaciones con el nombre de Principios Rectores sobre las Empresas y Derechos Humanos .

El Marco de las Naciones Unidas "Proteger, respetar y remediar" está basado en la interrelación de tres principios fundamentales:

- El Estado tiene la obligación de proteger a las personas frente a los abusos de los derechos huma- nos cometidos por terceros, incluidas las empresas, mediante medidas adecuadas, actividades de reglamentación y sometimiento a la justicia. Esa protección constituye la base misma del régimen internacional de derechos humanos.

- Las empresas tienen la obligación de respetar los derechos humanos, lo que significa actuar con la debida diligencia para no vulnerar los derechos de terceros y reparar las consecuencias negativas de sus actividades. Ese respeto encarna la expectativa social más elemental en relación con las empresas.

- Es necesario mejorar el acceso de las víctimas a vías de reparación efectivas, tanto judiciales como extrajudiciales, pues ni siquiera los esfuerzos mejor coordinados pueden impedir totalmente que se cometan abusos.

Sobre estos pilares se estructura un modelo dinámico que procura proponer a Estados y 
empresas las mejores prácticas para asegurar la efectividad de los derechos humanos. (Rulli \& Bautista Justo, 2012), así mismo Rivera Hernández, P. \& Marañón Lazcano, F. (2018) mencionan que una de las formas en que se puede lograr un establecimiento de una cultura de paz es a través de una mediación comunitaria por lo mismo es importante que se aparte de las acciones del gobierno como una política pública que contribuyan a la sociedad en un cambio cultural y permitan el respeto irrestricto de los derechos humanos.

El proceso que Ruggie ha llamado Principios Rectores se toma como fundamento para que las empresas y el estado cumplan con el respeto a la Consulta Previa Libre Informada (CPLI) a las comunidades indígenas, que son un caso específico de los grupos vulnerables.

\section{Los principios rectores de las Naciones Unidas sobre empresas y derechos Humanos}

Cantú Rivera (2017) menciona "El consenso sobre el respaldo unánime de los Principios Rectores sobre las empresas y los derechos humanos en el Consejo de Derechos Humanos en 2011, así como la renovación del mandato del Grupo de Trabajo en 2014 son una muestra de la trascendencia e importancia que este tema tiene en el escenario internacional, y del reconocimiento de la necesidad de que cada uno de los actores involucrados cumplan con sus respectivas responsabilidades."

Los principios rectores son una puesta en práctica del marco de las Naciones Unidas para "proteger, respetar y remediar"; son aplicados a todos los estados y a todas las empresas, tanto trasnacionales como de otro tipo, con independencia de su tamaño, sector, ubicación, propietarios y estructura y se basan en el reconocimiento de:

- $\quad$ El deber del estado de proteger los derechos humanos.

En este primer pilar se adentran los primeros principios (1-10) los cuales se pueden resumir de tal manera:

1. Protección por parte del estado, contra la violación de los derechos humanos cometidas en su territorio incluyendo las empresas.

2. Asegurarse que las empresas respeten los derechos humanos en todas sus actividades.

(Funciones reglamentarias y normativas del estado de carácter general)

3. Cumplir con la obligación de protección, haciendo cumplir las leyes que tengan por objeto cumplir con los derechos humanos, revisar que otras leyes no restrinjan el respeto a los DH por las empresas, así como asesorar, alentar o exigir a las empresas para que mediante sus actividades respeten los $\mathrm{DH}$.

(Nexo entre el estado y las empresas)

4. Nexo entre el estado y las empresas, a lo cual el estado debe adoptar medidas de protección contra las violaciones de los DH cometidas por empresas de su propiedad o bajo su control.

5. Los estados deben cumplir con sus obligaciones internacionales en DH cuando contratan los servicios de empresas.

6. El estado debe promover el respeto de los $\mathrm{DH}$ cuando realicen acuerdos comerciales.

(Fomentar el respeto de los derechos humanos por las empresas en zonas afectadas por con-

Revista Política, Globalidad y Ciudadanía, Vol. 5 No. 10, Julio - Diciembre 2019, Universidad Autónoma de Nuevo León, Monterrey, México, ISSN 2395-8448. 63-79. http://revpoliticas.uanl.mx/index.php/RPGyC/article/view/136 
flictos)

7. El estado debe asegurarse que las empresas que operan en zonas de conflicto, no se vean implicadas en abusos y violaciones de los DH.

(Garantizar la coherencia política)

8. Los estados deben asegurarse de que todo organismo que configuran en prácticas empresariales respeten y sean conscientes de las obligaciones de los $\mathrm{DH}$ del estado.

9. Los estados deben mantener un marco normativo nacional para asegurar el cumplimiento de sus obligaciones de DH, cuando exista algún tratado o contrato de inversión con las empresas.

10. Cuando el estado actúe en calidad de miembro de instituciones multilaterales debe asegurarse que las instituciones no se limiten a cumplir con la obligación de respetar los $\mathrm{DH}$, así mismo a alentarlos e inspirarse en los principios rectores para que exista cooperación internacional en la solución de problemas.

- La responsabilidad de las empresas de respetar los derechos humanos

En este segundo pilar se adentra la parte central de los principios (11-24) los cuales se pueden resumir de tal manera:

11. Las empresas deben de respetar los DH y afrontar consecuencias negativas si tienen alguna participación en la violación de estos.

12. La empresa tiene la responsabilidad de respetar los DH reconocidos internacionalmente y enunciados en la Carta Internacional de Derechos Humanos y en la Declaración de la OIT.

13. Las empresas deben evitar que con sus actividades provoquen la violación de los DH y prevenir las consecuencias negativas sobre los $\mathrm{DH}$ de acuerdo a su responsabilidad establecida.

14. La responsabilidad de las empresas de respetar los $\mathrm{DH}$ es independientemente de su tamaño, giro, contexto operacional, propietario o estructura.

15. Las empresas deben contar con políticas y procedimientos para cumplir con su responsabilidad de respetar los DH.

Compromiso Político

16. Las empresas deben expresar su compromiso de respetar los DH mediante una declaración de política que esté aprobada y se difunda interna y externamente.

La debida diligencia en materia de derechos humanos

17. Las empresas deben proceder con una diligencia en materia de DH, que incluya un impacto real y potencial de sus actividades, como actual al respecto y darle un seguimiento.

18. Las empresas deben identificar y evaluar las consecuencias negativas sobre los DH en las cuales puedan verse vinculados.

19. Las empresas deben integrar las conclusiones de sus evaluaciones de impacto en el marco de las funciones y procesos internos y tomar medidas oportunas.

20. Con el fin de verificar si se toman las medidas necesarias, las empresas deben hacer un seguimiento de la eficacia de su respuesta.

21. Las empresas deben explicar las medidas que toman ante las consecuencias de sus actividades y para esto deben estar preparadas para comunicarlas exteriormente.

Reparación

Revista Política, Globalidad y Ciudadanía, Vol. 5 No. 10, Julio - Diciembre 2019, Universidad Autónoma de Nuevo León, Monterrey, México, ISSN 2395-8448. 63-79. http://revpoliticas.uanl.mx/index.php/RPGyC/article/view/136 
22. Las empresas deben reparar o contribuir a su reparación por medios legítimos de las consecuencias negativas que llegasen a ocasionar.

Cuestiones de contexto

23. En cualquier contexto las empresas deben cumplir con todas las leyes aplicables, buscar formas para respetar los $\mathrm{DH}$, y considerar el riesgo de provocar o contribuir a violaciones graves de los $\mathrm{DH}$.

24. Cuando sea necesario las empresas deben dar prioridad a resolver las consecuencias negativas, reales y potenciales y tratar de prevenirlas.

- Acceso a mecanismos de reparación.

En este tercer pilar se adentra la parte final de los principios (25-31) los cuales se pueden resumir de tal manera:

25. Los estados deben tomar medidas apropiadas para garantizar, por las vías judiciales, administrativas, legislativas o de otro tipo que correspondan para que puedan acceder a mecanismos de reparación eficaces.

Mecanismos Judiciales Estatales

26. Los estados deben asegurar la eficacia de los mecanismos judiciales nacionales cuando existan violaciones de DH por parte de las empresas.

Mecanismos Extrajudiciales de Reclamación del Estado.

27. Los estados deben establecer mecanismos de reclamación extrajudiciales eficaces y apropiados, paralelamente a los mecanismos judiciales.

Mecanismos de reclamación No estatales

28. Los estados deben facilitar el acceso a los mecanismos de reclamación no estatales relacionado con los DH y las empresas.

29. Las empresas deben establecer o participar en mecanismos de reclamación eficaces de nivel operacional a disposición de las personas y las comunidades que se vean afectadas.

30. Los mecanismos de reclamación eficaces deben estar disponibles y ser garantizados por las corporaciones industriales, las colectividades de múltiples interesadas.

31. Los mecanismos de reclamación extrajudiciales, tanto estatales como no estatales, deben ser: legítimos, accesibles, predecibles, equitativos, transparentes, compatibles con los derechos, una fuente de aprendizaje continuo, basarse en la participación y el dialogo.

Finalmente podemos decir que los Principios Rectores los cuales fueron presentados en la sesión del Consejo de Derechos Humanos, son un informe de un experto que los ha distinguido por darle el seguimiento desde el momento que se llevó a cabo su implementación por diferentes actores especialmente por los Estados miembros de las Naciones Unidas, que ha dado paso a la firma de tratados internacionales en materia de Derechos Humanos, que dan un nuevo comportamiento desde la regulación estatal hasta las empresas trasnacionales.

\section{3.- MÉTODO}

Diseño

El enfoque investigativo de la presente investigación es cualitativo, de acuerdo con Hernán- 
dez, Batista y Fernández (2014) "Utiliza la recolección y análisis de los datos para afinar las preguntas de investigación o revelar nuevas interrogantes en el proceso de interpretación” (p.7).

Alcanzando un diseño no experimental "Que se realiza sin la manipulación deliberada de variables y en los que sólo se observan los fenómenos en su ambiente natural para después analizarlos” (Hernández, Batista y Fernández, 2014, p. 149).

El alcance establecido es el exploratorio "emplean cuando el objetivo consiste en examinar un tema poco estudiado o novedoso” (Hernández, Batista y Fernández, 2014, p. 91).

\section{Instrumentos}

Para la construcción del marco teórico-conceptual de la temática "Responsabilidad Social Empresarial a las Responsabilidades en Derechos Humanos", se consultaron un total de veinte referencias bibliográficas utilizándose como instrumento las ideas, argumentos y proyectos que fueron interpretados desde una perspectiva analítica y crítica.

\section{Procedimiento}

Con relación a la comprensión del problema de la investigación se recopilan fuentes secundarias de documentos académicos. En el marco de referencia se definen los conceptos básicos relativos a la Responsabilidad Social Empresarial. Una vez recopilada y analizada la información se construye el documento objeto de este trabajo. Por último, se realizan las recomendaciones y conclusiones conforme a los objetivos trazados (Bascón et al, 2016, p. 39).

\section{4.- CONCLUSIONES}

Con el fin de cumplir con su responsabilidad en el tema de Responsabilidad Social Empresarial, las empresas promueven la ejecución de acciones voluntarias de conducta con las cuales se compromete a respetar y cumplir las normas internacionales de derechos fundamentales como parte esencial de sus Políticas de RSE, sin embargo aún hay empresas que continúan obstaculizando la codificación de los derechos humanos y las obligaciones correspondientes involucrando a los diferentes sectores de la sociedad.

El tema de la medición de desempeño en estándares Derechos Humanos ha sido señalado como un aspecto que necesita mayor análisis y desarrollo a nivel internacional, por el Grupo de Trabajo de la ONU sobre empresas y derechos humanos, además de convertirlo en prioridad en su agenda. Para medir sus impactos, analizarlos y determinar la mejor manera de resolver los problemas que existen, las empresas se han valido de mecanismos como encuestas, herramientas de gestión, informes.

Con base a la teoría hemos visto que a nivel mundial se disponen de leyes que ponen a las empresas a mantener una línea en el respeto a los derechos humanos, pero aun así queda en duda si las autoridades de gobierno investigan las irregularidades que son cometidas por las 
empresas las cuales la única responsabilidad que se les invita a ejercer es respetar los derechos humanos, pero que en muchos casos por conseguir sus beneficios y éxitos en los proyectos es a costa de abuso contra el ser humano, uno de estos casos y el que nos interesa en esta investigación es el de las Comunidades indígenas que muchas de las veces se quedan en el intento para que se haga justicia, pero no tienen suficientes elementos por no tener el apoyo de los sistemas jurídicos, la corrupción, el no tener una información correcta y principalmente la gran relación entre el Estado y la Empresas.

Finalmente contrastando como lo indicaba Cantú Rivera con el establecimiento de un nuevo orden económico internacional a lo largo de los años la consagración de estándares laborales de RSE, aparece esta relación con los Derechos Humanos, con el único objetivo de que sean respetados estableciéndose en Organismos Internacionales a ir mas allá de una invitación a que sea una obligación de las empresas trasnacionales de respetar los $\mathrm{DH}$, siguiendo un código de conducta ya establecido.

Se han realizado avances importantes utilizando estrategias y metodologías que han sido usadas por las empresas para cumplir en los procesos del respeto a los derechos humanos en los grupos vulnerables, haciendo distintos intentos a lo largo del tiempo con el principal objetivo de que las empresas trasnacionales asuman su responsabilidad en proyectos de regulación internacional en el contexto del respeto a los derechos humanos.

\section{REFERENCIAS}

Adarme Durán, J. S., \& Maldonado Vásquez, J. A. La política fiscal y la RSE en Colombia.

Aguilera Castro, Adriana, \& Puerto Becerra, Doria Patricia. (2012). Crecimiento empresarial basado en la Responsabilidad Social. Pensamiento \& Gestión,(32), 1-26. Retrieved February 13, 2020, from http://www.scielo.org.co/scielo.php?script=sci_arttext\&pid=S1657$62762012000100002 \& \operatorname{lng}=$ en\&tlng=es.

Bascón, M.: Cazallo, A.; Lechuga, J. y Meñaca, I. (2016). Estudio de la necesidad de implantar un servicio público de transporte entre las ciudades de Ceuta-Tetuán y Melilla-Nador. En Desarrollo Gerencial Revista de la Facultad de Ciencias Económicas, administrativas y contables de la Universidad Simón Bolívar 8(2), 37 - 57.

Cantú Rivera, H. F. (2013). Empresas y derechos humanos: ¿hacia una regulación jurídica efectiva, o el mantenimiento del status quo? Anuario mexicano de derecho internacional, 13, 313-354. Recuperado en 25 de febrero de 2018, de http://www.scielo.org.mx/scielo. php?script $=$ sci_arttext\&pid=S187046542013000100007\&lng=es\&tlng=pt.

Cantú Rivera, H. (2017). Derechos humanos y empresas: reflexiones desde América Latina. Instituto Interamericano de Derechos Humanos.

CEMEFI. (2001). Decálogo postulado por las 17 empresas mexicanas portadoras del Distintivo ESR 2001 (Empresa Socialmente Responsable). México. 
Comité Minero Energético (CME) Guías Colombia en Empresas, DDHH y DIH, Pacto Global Red Colombia. (2019). Centro de Información Empresarial (CIEB). Recuperado el 12 de Febrero de 2020, de Cámara de Comercio de Bogotá: https://bibliotecadigital.ccb.org.co/ handle/11520/23426

Coparmex. (2006). Coparmex. Obtenido de ¿Que es la Fundación del Empresario en México?

Comisión Europea. (2001). Libro Verde, Fomentar un marco europeo para la responsabilidad social de las empresas. Bruselas.

Espinoza Santeli, M. G. (2016). La responsabilidad social empresarial en las micro, pequeñas y medianas empresas de Ecuador. Universidad Andina Simón Bolivar, 39-58.

Ghys, T. (2019). Spectacular and systematic human rights abuse in México. Revista Política, Globalidad y Ciudadanía, 5(9), 17-24. Recuperado de http://revpoliticas.uanl.mx/index. php/RPGyC/article/view/114

Gutiérrez, A. T. (2014). Empresas y Derechos Humanos. Derecho y Realidad, 2(24).

Hernández, R., Fernández, C., y Baptista, P. (2014). Metodología de la investigación. México: Mc Graw Hill.

Kliksberg, B. (2004). Pobreza, Un tema impostergable. FCE. PNUD. México

Ljubetic, Y. (2017). Empresas y Derechos Humanos. Gestión y Tendencias, 2(4), 2-3. doi:http:// dx.doi.org/10.11565/gesten.v2i4.48

Martínez, H. H. (2005). El marco ético de la responsabilidad social empresarial (pp. 2-11). Bogotá: Pontificia Universidad Javeriana, Colección Biblioteca del Profesional.

Rivera-Hernández, P. R., \& Marañon-Lazcano, F. d. (2018). The political communication as an influencer of public opinion on Human Rights issues. Case Study: San Salvador Atenco. Revista Política, Globalidad y Ciudadanía, 42-54. Recuperado de http://revpoliticas.uanl. mx/index.php/RPGyC/article/view/88.

Rulli, M., y Bautista Justo, J. (2012). Guía de derechos humanos para empresas: proteger, respetar y remediar: todos ganamos. Buenos Aires: Programa Naciones Unidas para el Desarrollo.

Torres, J. B., \& Alemán, L. S. (2020). La responsabilidad social de la empresa estatal en el ejercicio pleno de los derechos de los trabajadores en la empresa estatal en Cuba. REVISTA IUS, 14(45).

Vallaeys, F., De la Cruz, C., y Sasia, P. M. (2009). Responsabilidad social universitaria: manual de primeros pasos. Inter-American Development Bank. 